\title{
Development of an Innovative and Quality-Focused Production Technology for Magnesium Wire
}

\author{
Marie Moses ${ }^{1, a *}$, Claudia Kawalla, ${ }^{2, b}$, Rudolf Kawalla ${ }^{1, c}$ and Michael Höck ${ }^{2, d}$ \\ ${ }^{1}$ Institute of Metal Forming, TU Bergakademie Freiberg, Bernhard-von-Cotta-Str. 4, \\ 09599 Freiberg, Germany \\ ${ }^{2}$ Institute of Industrial Management, Operations and Logistics, Schlossplatz 1, \\ 09599 Freiberg, Germany

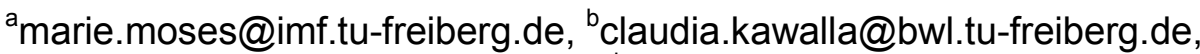 \\ crudolf.kawalla@imf.tu-freiberg.de, dmichael.hoeck@bwl.tu-freiberg.de
}

Keywords: magnesium wire production, quality features, twin-roll casting

\begin{abstract}
In order to meet customer requirements, technology developments need to stay focused at process rationalization and quality improvements. Combining the twin-roll casting technology and caliber rolling technology for magnesium wire, customer demands concerning cost-efficiency and high quality could be satisfied. For this purpose, the paper analyzes potential application fields and their demanded quality properties. Special requirements of illustrative magnesium long products are shown by adapting existing specifications of aluminum wire. The resulting long products could be applied in the automotive industry and aircraft sector as joining and welding elements or in biomedicine as screws. Finally, the innovative magnesium wire production technology will be explained and the advantages, in particular the resource efficiency, of the developed technology will be discussed.
\end{abstract}

\section{Introduction}

The aspired quality properties of magnesium wire depend strongly on the scope of utilization. Meeting customer requirements, magnesium wire needs to fulfill specific thermal, chemicalphysical and mechanical properties in combination with low production cost. A suitable production technology is twin-roll casting due to reduced process steps, high efficiency and improved product properties combining solidification and deformation in one process step. The resource-efficient technology, which has already been developed for magnesium strips at the Institute of Metal Forming (IMF) at the TU Bergakademie Freiberg [1], should be transferred to the production of magnesium long products by combining twin-roll casting and caliber rolling. Thereby, improved mechanical properties could be possible [2-4]. In contrast to common production routes like casting, extrusion [5,6] as well as equal channel angular extrusion (ECAE) [7], the new technology concept offers several competitive advantages, especially in the area of a large-scale, low cost production [3].

Within this paper, potential application fields of magnesium wire are described at first. Based on this, the paper provides an overview of the required quality features, which are adapted from aluminum wire, of the finished magnesium long product, in particular for welding wire and bolts. Finally, an explanation of the production concept for magnesium wire is given regarding the combination of the twin-roll casting technology and caliber rolling.

\section{Potential Application Fields}

Magnesium alloy wire has a high potential to be used as filler metal due to its good weldability. Welding wire is necessary to join magnesium components that are applied as lightweight materials in the automotive and aircraft sector. According to [8], there exist just a few magnesium alloy welding wires for laser welding processes. As welding wire should correspond to the base material, a need for magnesium welding wires in form of different alloys arises as there are innovative development trends regarding wrought magnesium alloys for sheets and profiles [9]. Another 
potential field of application in the same sector are joining elements for magnesium components, e.g., magnesium bolts and screws [10].

In case of biomedical application [11, 12], magnesium alloys containing aluminum are less suitable due to the toxicity of $\mathrm{Al}$ [13]. Aluminum-free magnesium alloys like $\mathrm{Mg}-\mathrm{Ca}-\mathrm{Mg}-\mathrm{Zn}-, \mathrm{Mg}-$ Si-, Mg-Sr- and Mg-RE-based alloys, which are more suitable for biodegradable implants, have lower mechanical properties in comparison to magnesium-aluminum alloys. However, magnesium alloy wire can be used in the field of additive manufacturing to produce biomedical implants, e.g. hip joints. In this context, the Wire Arc Additive Manufacturing process is a very promising method [14].

\section{Quality Properties of Magnesium Wire}

As illustrated, there are different application fields with varying requirements, which will be explained in this section. Quality standards must cover a wide range of aspects. However, no standard for magnesium wire requirements exists currently. Regarding geometric properties, form tolerance is a significant feature to ensure a better processing of the long product. To gain high surface quality, the material should not exhibit defects like cracks, seams, grooves. Chemical or physical properties mainly depend on the chemical composition, which influences, for example, the formation of segregations through a wider solidification range of low-melting phases. Furthermore, the microstructure evolution during production has an impact on the mechanical properties. Inner defects like pores or shrink holes can occur during processing, which negatively influence mechanical properties.

Being more specific, a catalogue of requirements for magnesium wire products need to be defined. According to [15], the mentioned technical criteria should be the basis for a quality evaluation. Table 1 summarizes some general quality features of magnesium wire, which are adapted from aluminum wire, wrought magnesium alloys and extruded magnesium products.

Table 1. Quality features of magnesium wire according to [15]

\begin{tabular}{|c|c|c|}
\hline \multirow{7}{*}{ Quality } & Surface & $\begin{array}{l}\text { According to DIN EN 1715-1 for aluminum alloys: } \\
\text { - No overfilling or sharp edges } \\
\text { - No laps or parting lines } \\
\text { - No dirt or foreign particles } \\
\text { - No abnormal oxide spots or burned }\end{array}$ \\
\hline & Shape & $\begin{array}{l}\text { Form tolerance and ovality according to DIN EN } 1715-1 \text { for } \\
\text { aluminum alloys }\end{array}$ \\
\hline & Mechanical Properties & According to DIN 9715 for wrought magnesium alloys \\
\hline & Microstructure & $\begin{array}{l}\text { - Rolling texture } \\
\text { - Small grain size (less or equal } 10 \mu \mathrm{m} \text { ) } \\
\text { - Equiaxed grains } \\
\text { - Homogeneity } \\
\text { - Small and fine distributed segregations }\end{array}$ \\
\hline & Chemical composition & $\begin{array}{l}\text { - Purity/alloying level according to ASTM B } 275 \\
\text { - Small and fine distributed segregations }\end{array}$ \\
\hline & Stresses & According to extruded magnesium alloys \\
\hline & Inner defects & $\begin{array}{l}\text { - No cracks } \\
\text { - Small pores } \\
\text { - No shrink holes } \\
\text { - No inclusions }\end{array}$ \\
\hline
\end{tabular}

Regarding the application as a filler material, magnesium welding wire should be free of defects like pores or shrink holes to avoid spattering during welding. Further, magnesium welding wire should have a homogenous chemical composition over the length, no impurities and a stable diameter to avoid discontinuities in the weld seam. The material should exhibit an equiaxed microstructure and a grain size as small as possible to avoid an abnormal grain growth during welding [16]. Fig. 1 shows an exemplary equiaxed grain structure of a commercial AZ61 magnesium alloy wire. The investigated mean grain size is about $19.8 \mu \mathrm{m} \pm 9.5 \mu \mathrm{m}$. 


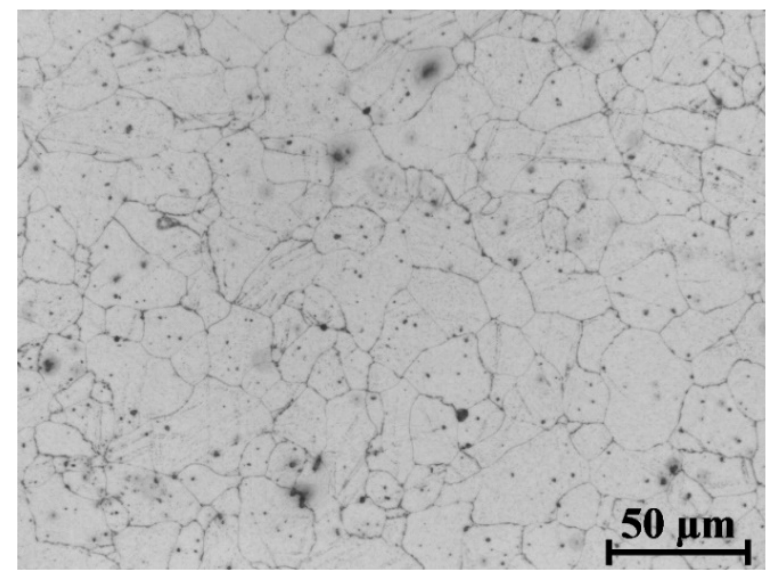

Fig. 1. Microstructure of AZ61 magnesium alloy welding wire

The welding wire diameter should be smaller than $2 \mathrm{~mm}$ because higher diameters lead to a higher energy use and a lower welding speed [8]. In the best case, the magnesium welding wire corresponds to the base material. Considering the mechanical properties, the tensile strength should vary from 270-290 MPa and the elongation should exhibit 11.5-15.5 \% [16].

Joining elements, like screws, should exhibit excellent mechanical properties, especially a high tensile strength. In contrast to an aluminum alloy A5056 screw with a tensile strength of $310 \mathrm{MPa}$, an AZ31 screw provides a lower tensile strength of $260 \mathrm{MPa}$ [16]. Comparing the elongation, the AZ31 screw shows a slightly higher value (8.5\%) than the A5056 screw (6.0\%) [16]. Hence, the material should be as free as possible of segregations as well as other inner or outer defects resulting in lower mechanical properties. In addition, shape tolerance is important to ensure the further processing. Moreover, a high clamping force is needed. Comparing an AZX912 aluminum alloy screw with an AZ31 magnesium alloy screw, the AZ31 screw has a higher clamping force [17]. If aluminum components are screwed together with magnesium screws [17], galvanic corrosion will occur, because a smaller area of a magnesium alloy is joined with a greater area of an aluminum alloy [18]. Spacers could minimize the problem [18], but corrosion protection layer solutions are needed.

In summary, there is a demand for a magnesium wire with small diameters and a high shape tolerance. Further, magnesium wire should exhibit a homogenous, fine microstructure, a clean, defect-free surface and a corrosion protection layer.

\section{Magnesium Wire Production by Twin-Roll Casting}

To meet the summarized quality requirements for magnesium wire, technology development should aim at different property levels. Due to a combination of process steps, the newly developed technology increases the productivity by reducing forming and annealing efforts. In contrast, conventional production routes exhibit more process steps. In case of twin-roll casting, production costs are scaled down and a continuous production of magnesium wire is possible. With respect to extrusion processes, a continuous production would not be possible. Concerning the twin-roll casting technology, the rapid solidification enables improved properties regarding homogeneity, finer microstructure, reduction of segregations and increased mechanical properties. Further, the technology could be applicable to various $\mathrm{Mg}$ alloys ensuring a broad range of application fields.

Overall, the innovative wire technology has economic and technological advantages compared to conventional technologies producing a competitive and high-quality magnesium wire. Fig. 2 depicts a comparison of the conventional and the new production technology. 


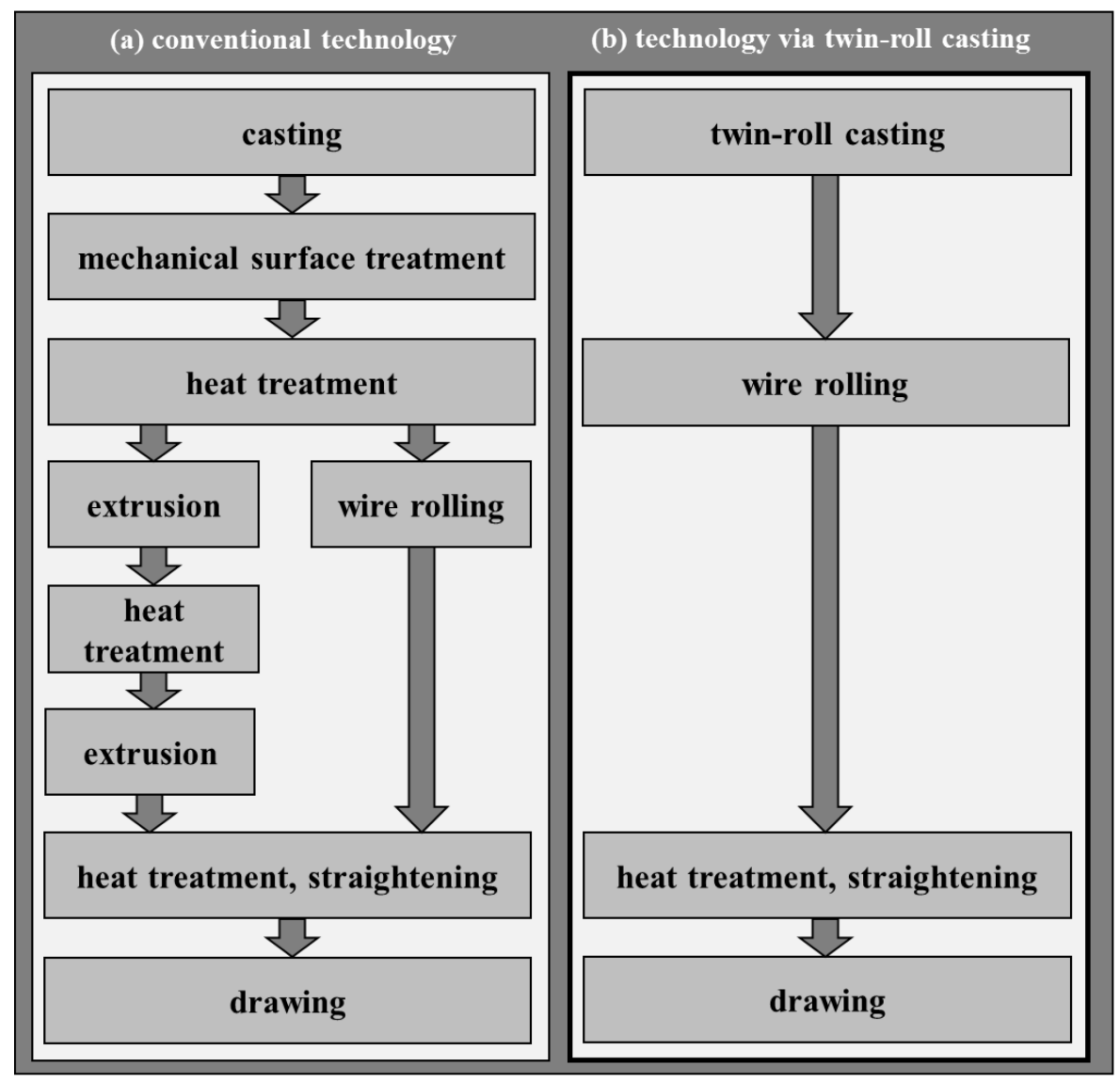

Fig. 2. (a) Conventional and (b) innovative production technology via twin-roll casting for magnesium long products

To develop a production technology via twin-roll casting for magnesium wire, a pilot plant has been built at TU Bergakademie Freiberg. The production concept of magnesium wire in a largescale demonstrator procedure at IMF is illustrated in Fig. 3.

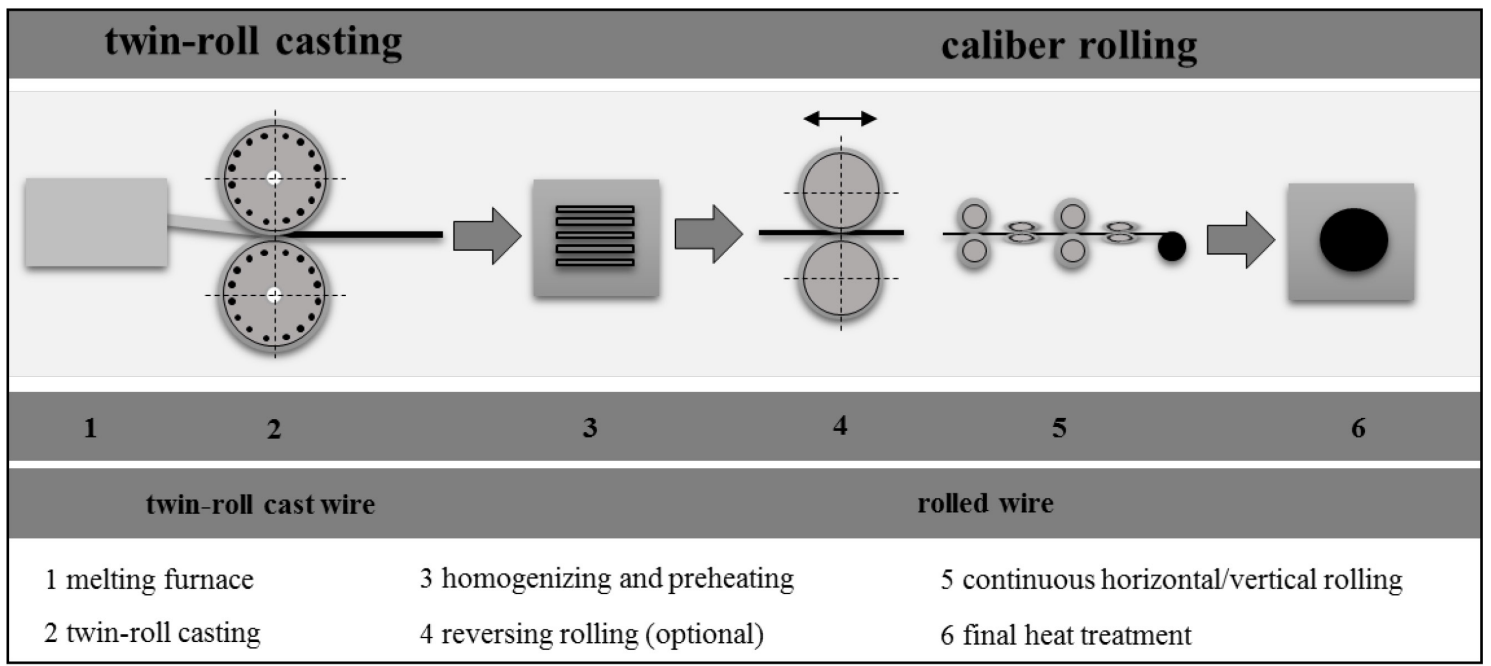

Fig. 3. Production process chain for the magnesium wire at the IMF

The production process consists of two steps, the twin-roll casting and caliber rolling. During twin-roll casting, magnesium ingots are melted under protective gas in a melting furnace. A constant melt level is held in the headbox to control the liquid stream. A nozzle continuously pours the liquid magnesium stream from the headbox into the roll gap of two counter-rotating, watercooled casting rolls. As the material solidifies in the roll gap, deformation occurs. Subsequently, the solidified and rolled magnesium wire is cooled under protective gas. 
After twin-roll casting, additional heat treatment is performed to achieve a homogenous microstructure. The heated twin-roll cast wire is caliber rolled in the second process stage by a reversing rolling mill at the IMF. The magnesium wire is rolled between a pair of rollers that have different kind of grooves included. By reducing the diameter, the wire is elongated. After every rolling pass, the wire is rotated $90^{\circ}$. Within eight passes, a reduction from an initial oval geometry, exhibiting a width of $20 \mathrm{~mm}$ and a height of $9.2 \mathrm{~mm}$, to a diameter of $6.5 \mathrm{~mm}$ is planned. Afterwards, the rolled wire is released for the continuous rolling mill, where the wire is rolled in four passes at rolling speeds that are comparable to industrial ones. The final aspired diameter at this stage is about $5 \mathrm{~mm}$. No additional heat treatment or lubricants are needed to deform the wire. After caliber rolling, magnesium wire is heat treated again to rebuild the forming capacity of the material and to adjust the required properties. It should be mentioned additionally, that a peeling of the material is a potential method of obtaining a clean and defect-free surface. Further hot or cold drawing processes using lubricants are possible to achieve small diameters below $2 \mathrm{~mm}$.

Previous investigations at the IMF analyzed the spread behavior of magnesium. A wider spreading of the material during caliber rolling is not desired because it is promoting defect formation. Results showed that spreading of a material depends on various impact factors like chemical composition of the material, deformation rate, deformation temperature, friction in the roll gap, longitudinal tensions, diagonal groove ratio and groove filling ratio [19].

\section{Conclusion}

Most conventional production routes for magnesium wire are too costly for a large-scale, industrial application. Hence, the potential fields of application and quality requirements for magnesium alloy wire need to be identified in a first technology development step. Analyzing existing requirements for aluminum wire, quality features of magnesium wire were indicated. As consequence, it was suggested that the developed technology could be ideally suitable for production of high-quality magnesium wire with superior properties. By combining resourceefficient twin-roll casting with grain-refining caliber rolling, it could be possible to ensure a largescale production with improved material properties and satisfying qualities.

To prove the technology concept, the IMF has built a pilot plant for twin-roll casting magnesium wire. Future investigations will deal with testing the developed concept of twin-roll casting in combination with caliber rolling by producing thin magnesium wire. Moreover, the research strategy concerning the technology development plans to combine the phenomenological approach with empirical studies using the partial least squares structural equation modeling approach (PLSSEM). Based on the results of this approach a customer-focused optimization of the technology can be carried out.

\section{Acknowledgment}

The authors would like to thank the European Regional Fond for financial support through the project No. 100270111.

\section{References}

[1] R. Kawalla, M. Oswald, C. Schmidt, M. Ullmann, H.-P. Vogt, N.D. Cuong, Development of a strip-rolling technology for $\mathrm{Mg}$ alloys based on the twin-roll-casting process, Magnesium Technol. (2008) 177-182.

[2] T. Mukai, H. Somekawa, T. Inoue, A. Singh, Strengthening $\mathrm{Mg}-\mathrm{Al}-\mathrm{Zn}$ alloy by repetitive oblique shear strain with caliber roll, Scripta Materialia 62 (2010) 113-116.

[3] Y. Tanno, T. Mukai, M. Asakawa, M. Kobayashi, Study on Warm Caliber Rolling of Magnesium Alloy, Material Science Forum 419-422 (2003) 359-364. 
[4] R.L. Doiphode, S. Narayana Murty, N. Prabhu, B.P. Kashyap, Effects of caliber rolling on microstructure and room temperature tensile properties of $\mathrm{Mg}-3 \mathrm{Al}-1 \mathrm{Zn}$ alloy, Journal of Magnesium and Alloys 1 (2013) 169-175.

[5] S.J. Liang, Z.Y. Liu, E.D. Wang, Microstructure and mechanical properties of Mg-Al-Zn alloy deformed by cold extrusion, Materials Letters 62 (2008) 3051-3054.

[6] Swiostek et al., Forming of Magnesium Alloys at $100{ }^{\circ} \mathrm{C}$ by Hydrostatic Extrusion, Journal of Materials Engineering and Performance 15 (2005) 705-711.

[7] Y. Yoshida, L. Cisar, S. Kamado, Y. Kojima, Effect of Microstructural Factors on Tensile Properties of an ECAE-Processed AZ31 Magnesium Alloy, Mater. Trans. 44 (2003) 468-475.

[8] X. Cao, M. Jahazi, J.P. Immarigeon, W. Wallace, A review of laser welding techniques for magnesium alloys, Journal of Materials Processing Technology 171 (2006) 188-204.

[9] S. You, Y. Huang, K.U. Kainer, N. Hort, Recent research and developments on wrought magnesium alloys, Journal of Magnesium and Alloys 5 (2017) 239-253.

[10]J. Dembinska, M. Graf, M. Ullmann, K. Neh, B. Awiszus, R. Kawalla, Property Oriented Wire Rolling Technology for Mg-Al Alloys, Key Engineering Materials 684 (2016) 42-56.

[11]J. Bai, L. Yin, Y. Lu, Y. Gan, F. Xue, C. Chu, J. Yan, K. Yan, X. Wan, Z. Tang, Preparation, microstructure and degradation performance of biomedical magnesium alloy fine wires, Progress in Natural Science: Materials International 24 (2014) 523-530.

[12]E. Willbold, A.A. Kaya, R.A. Kaya, F. Beckmann, F. Witte, Corrosion of magnesium alloy AZ31 screws is dependent on the implantation site, Materials Science and Engineering: B 176 (2011) 1835-1840.

[13]N. Li, Y. Zheng, Novel Magnesium Alloys Developed for Biomedical Application: A Review, Journal of Materials Science \& Technology 29 (2013) 489-502.

[14]J. Guo, Y. Zhou, C. Liu, Q. Wu, X. Chen, J. Lu, Wire Arc Additive Manufacturing of AZ31 Magnesium Alloy: Grain Refinement by Adjusting Pulse Frequency, Materials (Basel, Switzerland) 9 (2016).

[15]R. Kawalla, W. Lehnert, Qualität durch Umformung, Metalurgija 43 (2004) 169-179.

[16]L. Liu (Ed.), Welding and joining of magnesium alloys, Repr, Woodhead, Oxford, 2011.

[17]S. Hashimura, Y. Kurakake, Y. Miyashita, S. Yamanaka, G. Hibi, The Tightening Characteristics of Magnesium Alloy Bolts, Journal of Solid Mechanics and Materials Engineering 5 (2011) 732-741.

[18] G. Song, B. Johannesson, S. Hapugoda, D. StJohn, Galvanic corrosion of magnesium alloy AZ91D in contact with an aluminium alloy, steel and zinc, Corrosion Science 46 (2004) 955977.

[19]P. Adamyanets, M. Schmidtchen, R. Kawalla, Extension of the Freiberger Model of Spread for the Calculation of Material Flow during Rolling of Long Products to a New Material Group of Mg Alloys AZ31, AZ81, WE43, Key Engineering Materials 716 (2016) 677-684. 